Original Research Article

\title{
An introspection of quality of novel drug approvals by United States Food and Drug Administration
}

\author{
Rekha Mehani ${ }^{1}$, Ajay K. Shukla ${ }^{2 *}$
}

${ }^{1}$ Department of Pharmacology, R.K.D.F. Medical College, Bhopal, Madhya Pradesh, India ${ }^{2}$ Department of Pharmacology, All India Institute of Medical Sciences, Bhopal, Madhya Pradesh, India

Received: 09 October 2018

Revised: 28 October 2018

Accepted: 01 November 2018

*Correspondence to:

Dr. Ajay K. Shukla,

Email: ajay.pharm@ aiimsbhopal.edu.in

Copyright: (C) the author(s), publisher and licensee Medip Academy. This is an openaccess article distributed under the terms of the Creative Commons Attribution NonCommercial License, which permits unrestricted noncommercial use, distribution, and reproduction in any medium, provided the original work is properly cited.

\begin{abstract}
Background: United States Food and Drug Administration (FDA) is the fastest drug review agency in the world. FDA is responsible for protection of the public health by assuring that foods are safe, wholesome, sanitary and properly labelled. Approved Novel drugs are often innovative products that serve unmet medical needs or otherwise help to advance patient care.

Methods: FDA novel drug approvals were analysed from calendar year (CY) 2012 to 2016 on the basis of three criteria i.e., impact, access and predictability. Impact measured on the basis of: percentage of novel drug approvals (a) first in class (b) for rare diseases. Access measured on the basis of: percentage of novel drug approvals (a) first cycle approval (b) approval in the U.S. before other countries and (c) percentage of priority reviews. Predictability measured by: the percentage of novel drug approvals that met the PDUFA goal dates for the application review.

Results: Total number of novel drugs approved from CY 2012 to 2016 was 176 (average 35 novel drugs/ year). Impact of novel drug approvals: 40\% were first in class and $39 \%$ were for rare diseases. Access of novel drug approvals: $84 \%$ were first cycle approval, $60 \%$ were approval in US before other countries, $51 \%$ priority reviews among novel drug approvals. Predictability of novel drug approvals: $97 \%$ approvals able to meet PDUFA goal dates for application review. Conclusions: Novel drug approvals during CY 2012-2016 had a high quality which is very much evident by their high impact, good access and high predictability.
\end{abstract}

Keywords: BLA, FDA, Novel drug approvals, NDA, NME

\section{INTRODUCTION}

The Food and Drug Administration (FDA) is an agency within the U.S. Department of Health and Human Services. ${ }^{1}$ FDA is the fastest drug review agency in the world. ${ }^{2}$ Regulatory authority of FDA has very broad scope. FDA is responsible for protection of the public health by assuring that foods are safe, wholesome, sanitary and properly labelled. In general, FDA regulates foods, drugs, biologics, medical devices, electronic products that give off radiation, cosmetics, veterinary products, and tobacco products. ${ }^{1}$
First in Class (FIC) drugs are New Molecular Entities (NMEs) having chemical structures that have never been approved before. These are usually innovative products that play significant role in either serving previously unmet medical needs or advancement of patient care and public health. ${ }^{3}$ FIC drugs usually have different mechanism of action from those of existing therapies. These pharmacological agents with novel mechanism of action can be very useful in cases of patients who have not responded to existing therapies, cannot tolerate adverse effects of existing therapies or have developed resistance to available drugs. ${ }^{4}$ 
Worldwide approximately 350 million people are suffering from rare diseases. This magnitude can be better understood by assuming that if all the people suffering from rare diseases are living together in a country then it would be world's third most populous country. Distribution of patients suffering from rare diseases is skewed. There are 350 rare diseases responsible for $80 \%$ of the people suffering from rare diseases. New drug approvals for orphan disease can have significant impact which can be appreciated by the fact that there is not even a single approved treatment for 955 of these rare diseases. ${ }^{5}$

Impact of a novel drug approval can be assessed by its potential to meet unmet medical needs, unresponsive conditions not responding to existing therapies or conditions that have developed resistance or are refractory to the available therapies. Impact of a novel drug approval can be assessed by its effect on the present scenario of the treatment of the disease. Parameters that can assess impact of a novel drug approval are the drug approvals which are first in class (FIC) and drugs for the rare diseases or orphan novel drug approval.

The whole process from drug discovery to drug approval of a new drug takes on an average 10-15 years with an estimated cost of $\$ 1-2$ billion. The phase of clinical development typically takes around 6-7 years. Out of ten drugs that enters the phase of clinical trials; only one receives regulatory approval and is marketed. Since there is monumental cost and duration involved in clinical drug development, it becomes crucial to plan carefully and execute effectively. ${ }^{6}$ Earlier, there were high failure rates of initial drug submissions which was resulting in higher review timelines. To reduce these review timelines without compromising the approval standards, Prescription Drug User Fee Act (PDUFA) program was adopted. It has contributed significantly for the improvements of first cycle approval rates. ${ }^{2}$ First cycle approval indicates the novel drug approval on the "first cycle" of review, meaning without requests for additional information that would delay approval and lead to another cycle of review. This increase in first cycle approval rates has resulted in improved access of new drug approvals which will enhance performance of both FDA as well as pharmaceutical companies in terms of cost and time.

Flexible review practices without compromising with approval standards has also contributed to higher number of novel drug approvals in US before other countries. This has resulted in terms of higher access of innovative treatments to the US population before elsewhere in the world. $^{2}$

Drug discovery and development is a lengthy, risky and complex process. As per an estimate, out of every 5,00010,000 chemically synthesized molecules screened as potential drugs, only one receives an approval. ${ }^{6}$ As per PDUFA 1992, to improve drug review time FDA has adopted a two-tiered system of review times- priority reviews and standard reviews. Designation of priority review means that their approval would be significant improvements in the safety or effectiveness of the treatment, diagnosis, or prevention of serious conditions as compared to standard review. Priority review drugs have target review period of 6 months instead of 10 months. Priority review designation of a drug does not affect the quality of necessary evidence or the standards for approval. ${ }^{7}$ Thus, significance of designating priority review is evident by decreased review time results in higher access of novel drug approvals thus hastening their prospects of serving significant medical advances in health care.

Thus, quality parameters that can measure access of novel drug approvals are the first cycle approvals, approvals in US before other countries and priority review approvals

According to PDUFA, sponsors are assessed for user fees that will provide FDA, the additional resources to meet performance goals. PDUFA has authorized FDA for collecting fee from pharmaceutical companies for conducting reviews within targeted time frame. This allows appropriate allocation of additional resources by the FDA to meet performance goals. Thus, PDUFA has expedited the drug approval process hence improving predictability which is evident by novel drug approvals able to meet or exceed PDUFA goal dates for application review, agreed to with the pharmaceutical industry and approved by congress. ${ }^{8}$ Predictability of novel drug approvals ensures process reliability, thus encouraging and promoting research and drug development. High predictability of the drug approval process not only decreases the requirement of resources but also hastens the process of delivery of effective therapy the needy patients.

FDA has the highest rate of drug review than any other agency in the world. ${ }^{2}$ NMEs plays important role in offering new and innovative treatments to patients in need. ${ }^{3}$ Majority of the novel drug approvals are approved in the USFDA before their approval elsewhere in the world. Thus, worldwide FDA has got pivotal role regarding introduction of any innovative treatment. Although there have been studies analysing the quality of novel drug approvals on the yearly basis but none of the previous study has analyzed the quality of novel drug approvals on the longer-term basis. In this study, authors have analyzed the quality of novel drug approvals on the basis of impact, access and predictability during the period of five years from CY 2012 to 2016. In this study, authors have evaluated quality of FDA novel drug approvals during CY 2012 to 2016.

\section{METHODS}

The information was obtained about regulatory approvals of novel drugs by the U.S. FDA from publicly accessible databases. 9 The definition of "new molecular entities" included both New Drug Applications (NDAs) and Biologics License Applications (BLAs). The information about original new drug approvals (NDAs and BLAs) was 
retrieved from CY 2012 to 2016. Original abbreviated new drug approvals (ANDAs) and supplemental approvals were not included for analysis. The obtained information was analysed using a Microsoft Excel worksheet.

Authors evaluated quality of FDA novel drug approvals from CY 2012 to 2016 on the basis of three parameters i.e., their impact, access and predictability. ${ }^{10}$

Impact of novel drug approvals was assessed on the basis of two parameters: percentage of novel drug approvals which were (a) FIC (b) for rare diseases.

Access was assessed on the basis of three parameters: percentage of novel drug approvals which were (a) first cycle approval (b) approval in the U.S. before other countries and (c) priority reviews. ${ }^{10}$

Predictability was assessed on the basis of percentage of novel drug approvals which were able to meet the PDUFA goal dates for the application review.

\section{RESULTS}

Authors evaluated the quality of novel drug approvals during CY 2012- 2016 in terms of total number of novel drug approvals, their impact, access and predictability in the above-mentioned period. Total number of novel drugs approved during CY 2012 to 2016 was 176. Average number of novel drugs approvals during the CY 210122016 is 35 novel drugs per year (Table 1 and 2).

Table 1: Novel new drug approvals from calendar year 2012 to 2016.

\begin{tabular}{|ll|}
\hline Calendar Year & Novel drug approvals \\
\hline 2012 & 39 \\
\hline 2013 & 29 \\
\hline 2014 & 41 \\
\hline 2015 & 45 \\
\hline 2016 & 22 \\
\hline Total drug approvals & 176 \\
\hline
\end{tabular}

Table 2: Novel drugs approved from calendar year 2012 to 2016.

\begin{tabular}{|c|c|}
\hline $\begin{array}{l}\text { Calendar } \\
\text { year }\end{array}$ & Approved novel drugs \\
\hline 2012 & $\begin{array}{l}\text { Amyvid, Aubagio, Belviq, Bosulif, Choline C-11, Cometriq, Elelyso, Eliquis, Erivedge, Fulyzaq, } \\
\text { Fycompa, Gattex, Iclusig, Inlyta, Jetrea, Juxtapid, Kalydeco, Kyprolis, Linzess, Myrbetriq, Neutroval, } \\
\text { Omontys, Perjeta, Picato, Prepopik, raxibacumab, Signifor, Sirturo, Stendra, Stivarga, Stribild, Surfaxin, } \\
\text { Synribo, Tudorza pressair, Voraxaze, Xeljanz, Xtandi, Zaltrap, Zioptan }\end{array}$ \\
\hline 2013 & $\begin{array}{l}\text { Actemra, Adempas, Anoro Ellipta, Apitom, Breo Ellipta, Brintellix, Dotarem, Duavee, Gazyva, Gilotrif, } \\
\text { Imbruvica, Invokana, Kadcyla, Kynamro, Luzu, Lymphoseek, Mekinist, Nesina, Olysio,Opsumit, } \\
\text { Osphena, Pomalyst, Sovaldi, Simponi, Tafinlar, Tecfidra, Tivicay, Vizamyl, Xofigo }\end{array}$ \\
\hline 2014 & $\begin{array}{l}\text { Akynzeo, Beleodaq, Belsomra, Blincyto, Cerdelga, Cyramza, Dalvance, Entyvio, Esbriet, Farxiga, } \\
\text { Harvoni, Hetlioz, Impavido, Jardiance, Jublia, Kerydin, Keytruda, Lumason, Lynparza, Movantik, } \\
\text { Myalept, Neuraceq, Northera, Ofev, Opdivo, Orbactiv, Otezla, Plegridy, Rapivab, Sivextro Sylvant, } \\
\text { Striverdi Respimat, Tanzeum, Trulicity, Viekira Pak Vimizim, Xtoro, Zerbaxa, Zontivity, Zydelig, } \\
\text { Zykadia, }\end{array}$ \\
\hline 2015 & $\begin{array}{l}\text { Addyi, Alecensa, Aristada, Avycaz, Bridion, Cholbam, Corlanor, Cosentyx, Cotellic Cresemba, Daklinza, } \\
\text { Darzalex, Empliciti, Entresto, Farydak, Genvoya, Ibrance, Kanuma, Kengreal, Kybella, Lenvima, Lonsurf, } \\
\text { Natpara, Ninlaro, Nucala, Odomzo, Orkambi, Portrazza, Praluent, Praxbind, Repatha, Rexulti, Savaysa, } \\
\text { Strensiq, Tagrisso, Tresiba, Unituxin, Uptravi, Varubi, Veltassa, Viberzi, Vraylar, Xuriden, Yondelis, } \\
\text { Zurampic }\end{array}$ \\
\hline 2016 & $\begin{array}{l}\text { Adlyxin, Anthim, Axumin, Briviact, Cinqair, Defielio, Epclusa, Eucrisa, Exondys 51, Lartruvo, Netspot, } \\
\text { Nuplazid, Ocaliva, Rubraca, Spinraza, Taltz, Tecentriq, Venclexta, Xiidra, Zepatier, Zinbryta, Zinplava }\end{array}$ \\
\hline
\end{tabular}

Impact of novel drug approvals during CY 2012 to 2016 was measured in terms of FIC and drug approvals for rare diseases. There were $40 \%$ novel drug approvals which were FIC during this period. In this tenure of five years between CY 2012 to 2016, 38\% of the novel drug approvals were for the drugs for rare diseases (Table 3).

Access of novel drug approvals during CY 2012 to 2016 was measured in terms of first cycle approvals, approvals in the US before other countries, and percentage of priority reviews. During this period, $84 \%$ of the novel drug approvals were first cycle approvals and $59 \%$ of the novel drug approvals were approvals in the US before other countries. Percentage of priority reviews among novel drug approvals, during this period, was 51\% (Table 4 and Figure 1).

Predictability of novel drug approvals during CY 2012 to 2016 was measured in terms of novel drug approvals which were able to meet or exceed PDUFA goal dates. During 
this period, $97 \%$ of approvals were able to meet or exceed PDUFA goal dates for application review (Table 5).

Table 3: Impact of the novel drugs approved from calendar year 2012 to 2016.

\begin{tabular}{|lll|}
\hline Calendar year & First in class & $\begin{array}{l}\text { Drugs for } \\
\text { rare disease }\end{array}$ \\
\hline 2012 & $20(51 \%)$ & $13(33 \%)$ \\
\hline 2013 & $9(31 \%)$ & $9(31 \%)$ \\
\hline 2014 & $17(41 \%)$ & $17(41 \%)$ \\
\hline 2015 & $16(36 \%)$ & $21(47 \%)$ \\
\hline 2016 & $8(36 \%)$ & $7(41 \%)$ \\
\hline Total drug approvals & $70(40 \%)$ & $67(38 \%)$ \\
\hline
\end{tabular}

Table 4: Access of the novel drugs approved from calendar year 2012 to 2016.

\begin{tabular}{|c|c|c|}
\hline Calendar year & $\begin{array}{l}\text { First cycle } \\
\text { approval }\end{array}$ & $\begin{array}{l}\text { Approval in US } \\
\text { before other } \\
\text { countries }\end{array}$ \\
\hline 2012 & $31(79 \%)$ & $30(77 \%)$ \\
\hline 2013 & $24(83 \%)$ & $10(34 \%)$ \\
\hline 2014 & $32(78 \%)$ & $26(63 \%)$ \\
\hline 2015 & $39(87 \%)$ & $29(64 \%)$ \\
\hline 2016 & $21(95 \%)$ & $19(86 \%)$ \\
\hline Total drug approvals & $147(84 \%)$ & $104(59 \%)$ \\
\hline
\end{tabular}

Table 5: Predictability of novel drugs approved from calendar year 2012 to 2016.

\begin{tabular}{|ll|}
\hline Calendar year & PDUFA target dates met \\
\hline 2012 & $37(97 \%)$ \\
\hline 2013 & $29(100 \%)$ \\
\hline 2014 & $40(98 \%)$ \\
\hline 2015 & $43(96 \%)$ \\
\hline 2016 & $21(95 \%)$ \\
\hline Total drug approvals & $170(97 \%)$ \\
\hline
\end{tabular}

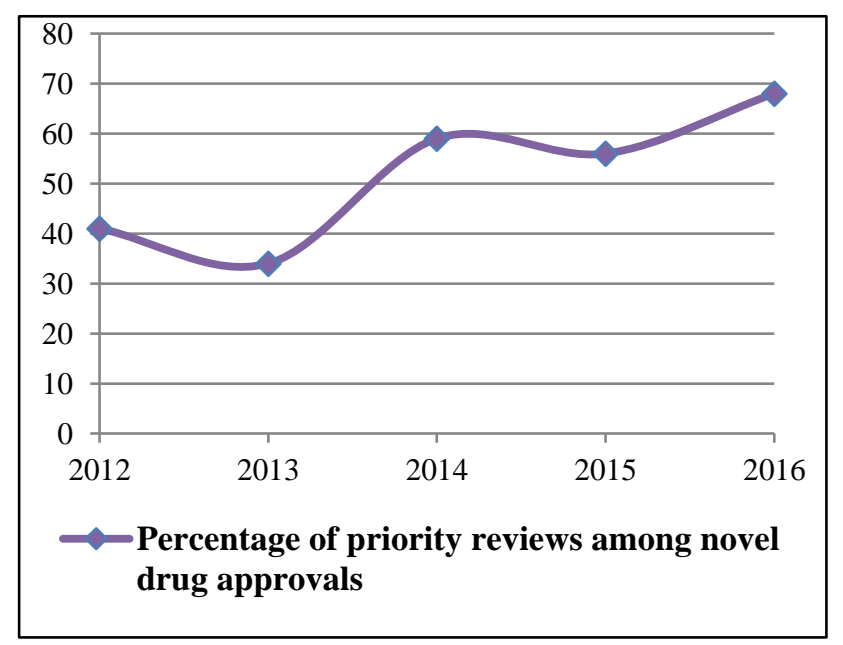

Figure 1: Percentage of priority reviews among novel drug approvals.

\section{DISCUSSION}

During the period of CY 2012-2016, there were 176 novel drug approvals with an average of 35 novel drug approvals per year. The novel drug approvals during this period had high impact which is evident by the fact that these drug approvals were $40 \%$ FIC and 38\% for orphan diseases. There was good access of novel drug approvals which is clearly evident by the $84 \%$ first cycle approvals, $51 \%$ priority reviews and $59 \%$ approvals in US before other countries. There was high predictability evident by the fact that $97 \%$ of novel drug approvals were able to meet PDUFA goal dates.

There were 176 novel drug approvals from CY 2012 to 2016 (35 novel drug approvals per year) while during the period of CY 2007 to 2011, there were only 119 novel drug approvals (24 novel drug approvals per year). Thus, as compared to period of CY 2007 to 2011, during the period of CY 2012 to 2016, there was rise in the total number of novel drug approvals (from 119 during CY 2007-2011 to 176 during CY 2012-2016) with a significant rise in average number of novel drug approvals per year (from 24 during CY 2007-2011 to 45 during CY 2012-2016) (Figure 2). ${ }^{9}$

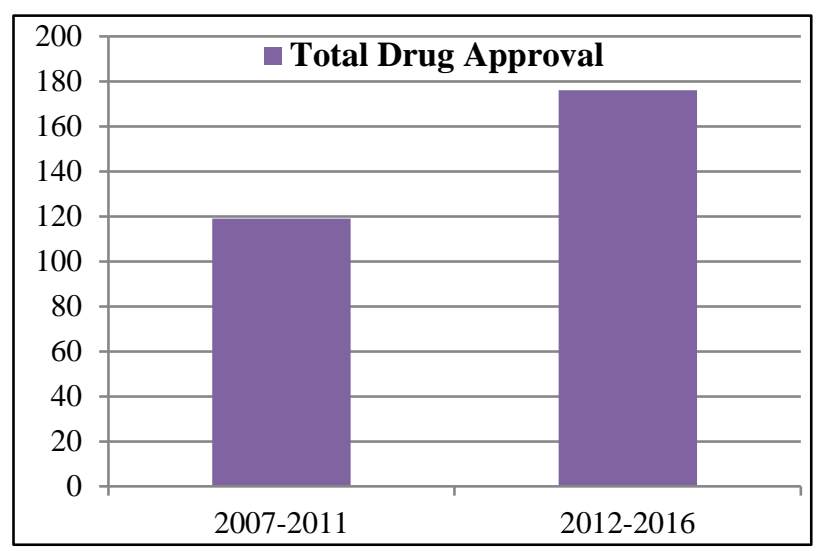

Figure 2: Novel drug approvals during CY 2007-2011 and 2012-2016.

Impact of the novel drug approvals is a measure of their potential positive impact and unique contributions to quality medical care and public health. ${ }^{6}$ FIC drugs offer new therapeutic options for the treatment of previously untreatable conditions. There were $40 \%$ of first in class novel drug approvals thus offering new therapeutic options for the offer new treatment of previously untreatable diseases. Thus, overall 70 first in class were approved during the span of period from CY 2012-2016 offering new treatment options which were previously not available. Thus, first in class drugs have impact by providing their unique contributions towards public health.

There are about 350 million people are suffering from rare diseases all over the world and less than $5 \%$ of these rare diseases have approved treatments. Orphan drug act 1983 provides incentives to companies developing treatments 
for these rare or orphan diseases. ${ }^{5}$ There were fewer than 10 drugs for rare diseases in 1970s while now a days, more than 400 drugs have been approved for the treatment of rare diseases. By March 2017, 599 have been drug approvals has been designated orphan drug status. ${ }^{11}$ According to National Institute of Health estimates about $50 \%$ of people affected by rare disease are children. About $30 \%$ of children suffering from rare disease die before their fifth birthday and $35 \%$ of deaths caused by the rare diseases occur within the first year of life., ${ }^{5,12}$ During CY 2012 to 2016, there were $39 \%$ of the novel drug approvals for the rare or orphan diseases. ${ }^{9}$ There were only 40 novel drug approvals for rare diseases between 2007-2011 while there were 67 novel drug approvals during the period of 20122016 for these diseases which means this much higher number of treatment options became availed for the patients suffering from rare diseases (Figure 3).

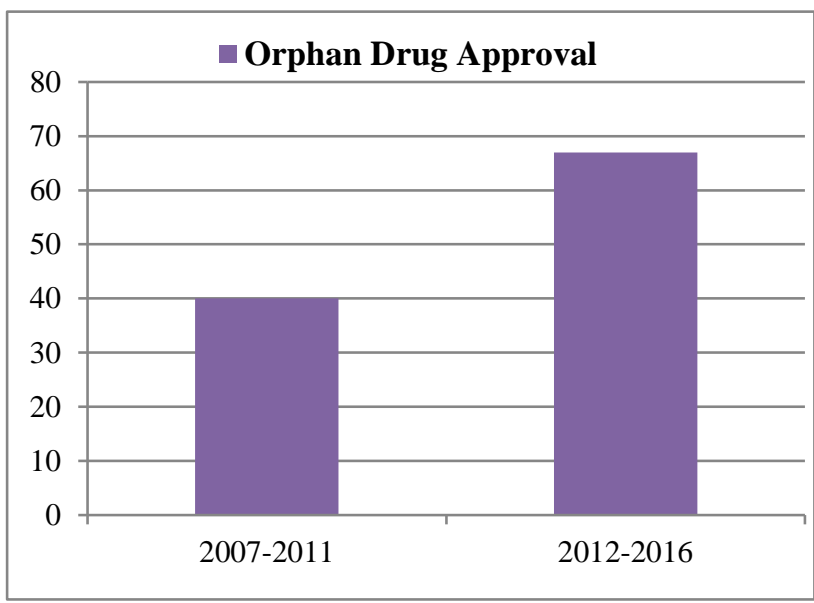

Figure 3: Orphan drug approvals during CY 20072011 and 2012-2016.

New drug development is a lengthy and costly process. The cost of discovering and developing a new drug are estimated to be around $\$ 1.2$ billion while according to some estimates its cost have been found to be up to $\$ 5$ billion. Out of 10,000 chemical compounds considered as promising at initial screening assays, fewer than ten make it to clinical phase and eventually, approval is achieved by only two. ${ }^{6}$ Among novel drug approvals, there were $84 \%$ first cycle approvals, as a marker of high access. First cycle approvals may be viewed as a proxy for either for quality of the submitted FDA new drug applications, willingness of FDA to approve new drugs or both. ${ }^{13}$ There has been sustained improvement in the number of first cycle approvals from CY 2008 to 2016.9.13

Comparing novel drug approval in the US before other countries offers another measure of access. Although there are wide differences in the regulatory processes of FDA and those of regulatory agencies in other countries, comparison of approval to other countries offers another measure of approval efficiency. ${ }^{3}$ There were $59 \%$ novel drug approvals in the US before other countries during CY
2012 to 2016.These innovative treatment options became available in the US before any other country in the world.

Priority reviews is a mode for allocating staff and resources for promoting access for innovativeness. FDA decides on the review designation for every application. Priority review designation leads to decreased duration of 6 months to review application instead of 10 months duration for standard review. ${ }^{7}$ This had encouraged earlier access of newer innovative drug treatment without compromising with approval standards.

The main objective of PDUFA is to allocate additional resources for ensuring safe and effective medicine availability in a timely manner. By ensuring adequate staffing and resources availability, PDUFA implementation has improved consistency, predictability and efficiency of FDA reviews. As per PDUFA, FDA can hire more reviewers to facilitate more reviews and meetings. PDUFA $\mathrm{V}$ has mandated the frequent communications between FDA and sponsor. This can be one of the promoting factor for the consistently high first cycle approvals and the ability to meet PDUFA target dates. ${ }^{14}$ There were $97 \%$ novel drug approvals which were able to meet their target date which indicates high predictability.

Thus, authors can implicate various factors for the quantitative as well as qualitative improvement of novel drug approvals.

- Orphan drug act 1992 under which various incentives are provided to the pharmaceutical companies contributing to the orphan drug discovery and development.

- Assigning the designation of priority reviews and decreasing their review time from ten months to six months.

- PDUFA-this act is renewed every five years and it makes changes appropriate to facilitate the drug approval process without compromising with quality standards. With time, PDUFA has mandated the frequent communications of FDA with the applicant pharmaceutical companies of drug approval. This has progenerated into higher access of applicants to FDA and henceforth, higher number of first cycle approvals.

- More flexible drug review process of the FDA than any other country without compromising approval standards has played pivotal role in the approval of innovative drugs in US before other countries.

\section{CONCLUSION}

There have been high impact, good access and high predictability of novel drug approvals during CY 20122016. During the period of CY 2012 to 2016, there was significantly high percentage of novel drug approvals which were first in class (40\%) and for rare diseases (39\%) signifying their positive impact and unique contributions to quality care and public health. There was high percentage 
of first cycle approvals (84\%) and of approvals in U.S. before other countries $(60 \%)$, higher priority reviews $(51 \%)$ as compared to standard drug reviews signifying sustained good access for FDA novel drug approvals. More than $95 \%$ (97\%) of novel drug approvals were able to meet the PDUFA goal dates for the application review year reaching signifying consistently high predictability. In this study, we analyzed the quality of novel drug approvals by using parameters impact, predictability and access for a span of last five years only. This improvement is encouraging but it is early to anticipate that it reflects long term trends. We can plan further studies of longer span to look out for the trends in impact, predictability and access of FDA novel drug approvals.

Funding: No funding sources

Conflict of interest: None declared

Ethical approval: Not required

\section{REFERENCES}

1. What does FDA do? 2018. Available at: https://www.fda.gov/AboutFDA/Transparency/Basics /ucm194877.htm. Accessed 02 January 2018.

2. Speed Up Drug Approvals? FDA Already Did. ? 2017 Available at: https://www.nbcnews.com/health/health-news/speeddrug-approvals-fda-already-did-n715481. Accessed 02 January 2018.

3. Novel Drugs 2015 Summary. 2016. Available at: https://www.fda.gov/downloads/drugs/developmenta pprovalprocess/druginnovation/ucm485053.pdf. Accessed 02 January 2018.

4. Innovation in the Biopharmaceutical Pipeline: A Multidimensional View. 2013. Available at: http://phrma-

docs.phrma.org/sites/default/files/pdf/2013innovation inthebiopharmaceuticalpipelineanalysisgroupfinal.pdf. Accessed 02 January 2018.

5. Rare Diseases-A Report on orphan Drugs in the pipeline. 201. Available at: http://phrmadocs.phrma.org/sites/default/files/pdf/Rare_Diseases_ 2013.pdf. Accessed 02 January 2018.

6. Vahle JL, Hutto DL, Postema M. Drug Discovery and Preclinical Development. In: Golan DE, Armstrong
EJ, Armstrong AW, eds. Principles of Pharmacology. 4th ed. Philadelphia: Wolters Kluwer Health 2017:919-32.

7. Priority Review. 2018. Available at: https://www.fda.gov/forpatients/approvals/fast/ucm4 05405.htm. Accessed 08 January 2018.

8. New Drug Application (NDA). 2016. Available at: https://www.fda.gov/Drugs/DevelopmentApprovalPr ocess/HowDrugsareDevelopedandApproved/Approva 1Applications/NewDrugApplicationNDA/default.htm. Accessed 02 January 2018.

9. Drugs@FDA: FDA Approved Drug Products. 2018, Available at: https://www.accessdata.fda.gov/scripts/cder/daf/inde x.cfm. Accessed 02 January 2018

10. 2016 Novel Drug Approvals. 2017. Available at: https://www.fda.gov/downloads/Drugs/Development ApprovalProcess/DrugInnovation/UCM536693.pdf.

11. Search Orphan Drug Designations and Approvals. 2018. Available at: https://www.accessdata.fda.gov/scripts/opdlisting/oo pd/listResult.cfm. Accessed 08 January 2018.

12. 2013 Novel New Drugs Summary. 2014. Available at: https://www.fda.gov/downloads/Drugs/Development ApprovalProcess/DrugInnovation/UCM381803.pdf. Accessed 08 January 2018.

13. Report: FDA Drug, Device Approval Times Improving. 2015. Available at: https://www.raps.org/news-articles/newsarticles/2015/1/report-fda-drug,-device-approvaltimes-improving. Accessed 08 January 2018.

14. PDUFA Reauthorization Performance Goals and Procedures Fiscal Years 2013 Through 2017. Available https://www.fda.gov/downloads/ForIndustry/UserFee s/PrescriptionDrugUserFee/UCM270412.pdf. Accessed 08 January 2018.

Cite this article as: Mehani $\mathrm{R}$, Shukla AK. An introspection of quality of novel drug approvals by United States Food and Drug Administration. Int J Basic Clin Pharmacol 2019;8:84-9. 